I Universidad Nacional de Córdoba-CONICET,

Instituto de Antropología de Córdoba, Museo de Antropología,

Nueva Córdoba, Córdoba, Argentina

femagaldi@gmail.com

https://orcid.org/0000-0002-1905-5365

Felipe Magaldi'

\title{
A PSICANÁLISE CONTRA A PAREDE: ENTREVISTA COM GILBERTO VELHO
}

Velho, Gilberto. (1978). A psicanálise contra a parede. Rádice - Revista de Psicologia, ano 2, n. 8, p. 35-37. Entrevista concedida ao comitê editorial da Rádice.

\section{APRESENTAÇÃO}

Rádice foi uma publicação carioca produzida por universitários de psicologia entre I976 e I98I, período marcado pela ditadura militar no Brasil. Sua vocação crítica se manifestou pela abordagem de temas considerados polêmicos para a época - dentre os quais se destacou a denúncia da repressão política e das condições degradantes dos hospitais psiquiátricos do país, além de questões de gênero, sexualidade, família, religião, juventude e comportamento - e por sua participação ativa no comitê de imprensa alternativa, que amalgamava os jornais independentes que proliferavam naquele contexto. Os nomes de Jurandir Freire Costa, Nise da Silveira, Helio Pellegrino, Félix Guattari, Ronald Laing, Carl Rogers, Franco Basaglia e Wilhelm Reich foram alguns dos que ecoaram nas entrelinhas dos artigos e entrevistas publicados nos I5 números da revista.

Embora de importância intelectual e afetiva para a geração que se graduou na área no período em questão, o material de Rádice permaneceu por muito tempo disperso em sebos, baús e arquivos pessoais, ausentando-se de quaisquer acervos institucionais. Em 2008, a pesquisa de doutorado de Alessandra Daflon dos Santos, defendida no Programa de Pós-Graduação em Psicologia Social da Uerj sob a orientação da professora Ana Maria Jacó-Vilela, veio a reverter esse quadro (Santos, 2008; Santos \& Jacó-Vilela, 2006). Graças à doação de Carlos Ralph - também conhecido como Cê Ralph, um dos membros fundadores da revista, que se destacaria posteriormente como terapeuta cor- 
poral de orientação reichiana - sua coleção completa pode ser hoje consultada na biblioteca do Clio-Psyché, núcleo sediado, desde I998, no mesmo departamento em que se concluiu a referida investigação. ${ }^{\text {I }}$ Trata-se de um programa especializado em estudos sobre a história da psicologia no Brasil, que promove continuamente eventos e publicações. ${ }^{2}$

O presente documento consiste em transcrição de uma entrevista realizada com o antropólogo Gilberto Velho (I978), publicada na revista Rádice em I978. Trata-se de depoimento que condensa de forma privilegiada algumas das principais questões que perpassavam a agenda da então nascente antropologia urbana no Rio de Janeiro, com particular destaque para sua proposta de abordagem dos saberes psicológicos (psiquiatria, psicologia e psicanálise) sob a égide da problemática indivíduo/sociedade. A entrevista, intitulada A psicanálise contra a parede, apresentada por Ralph, foi divulgada justamente no intervalo produtivo entre a coletânea Desvio e divergência (Velho, I974) e o livro Individualismo e cultura (Velho, I98I), que figuram entre as mais destacadas obras do autor a propósito desse tema.

Além dessa questão geral, chama a atenção nessa publicação a referência a um importante evento ocorrido em outubro de I978, o Io Simpósio Internacional do Instituto Brasileiro de Psicanálise, Grupos e Instituições Ibrapsi, fundado por Gregório Baremblitt, Luís Fernando Melo Campos e Chaim Katz em prol da oposição às instituições oficiais de psicanálise e do convênio com outros saberes, como as ciências sociais em geral. O simpósio, realizado no Hotel Copacabana Palace, reuniu figuras tais como Erving Goffman, Howard Becker, Thomas Szasz, Robert Castel, Félix Guattari, Franco Basaglia, Peter Fry e Shere Hite, além do próprio Gilberto Velho. ${ }^{3}$

$\mathrm{Na}$ entrevista, realizada poucos dias após o congresso, o antropólogo carioca deixa entrever que a relação entre antropologia e psicanálise estabelecida nesse contexto estava longe de coincidir com uma aliança pacífica. Tratava-se, antes, de um exercício crítico que, do ponto de vista comparativo das ciências sociais, ensejaria a desestabilização dos pressupostos universalistas dos saberes "psi" e da visão de mundo individualista comprometida com sua difusão. O relativismo cultural, nesse programa, afigurava-se em seu sentido forte e provocador, não apenas descrevendo práticas situadas em determinada configuração sócio-histórica a partir de um olhar "distanciado", mas promovendo potenciais intervenções em seus desdobramentos.

Embora não esteja explícito no conteúdo desse documento, a perspectiva antropológica despertou grande interesse de alguns profissionais do próprio campo psicanalítico carioca nesse lapso, em especial de Sérvulo Figueira que, junto com Gilberto Velho, consolidou um campo de pesquisas interdisciplinar a partir dos anos I970 envolvendo instituições como o Museu Nacional da UFRJ, o Instituto de Medicina Social da Uerj, o Instituto de Psiquiatria da UFRJ e a Pós-Graduação em Psicologia Clínica da PUC-RJ (ver Figueira, I978, I980, I98I; 
Figueira \& Velho, I98I). Os temas do estigma e do desvio, caros à discussão da Escola de Chicago, assim como a problemática do individualismo, na esteira das contribuições de Marcel Mauss, Louis Dumont e Georg Simmel, entre outros autores, constituíram os principais feixes de articulação dessas searas. Antropologia e psicanálise encontravam-se então em um momento de intenso desenvolvimento na metrópole do Rio de Janeiro, tendo como pano de fundo comum as agitações contraculturais e a luta pela redemocratização do país (Duarte, I996; 2000; Russo, 2004). Essa linha de trabalho, afeita ao estudo da vida urbana e da modernização, se desenrolou regularmente até o final da década de I980, contando ainda com a especial contribuição de Luiz Fernando Dias Duarte (I986) sobre a construção social da pessoa nas classes trabalhadores urbanas. Embora não siga existindo atualmente enquanto movimento sistemático, sua configuração original permanece influente na expansão do campo da antropologia no Brasil, sobretudo na interseção entre temas tais como corpo, pessoa, saúde, doença, ciência, religião, gênero e sexualidade.

Agradecimentos especiais devem ser enviados a Ana Jacó-Vilela e a Charles William Mello, que gentilmente cederam o material para consulta, e a Luiz Fernando Dias Duarte, que ajudou a confirmar a composição de uma das mesas do simpósio (fig. 3).

\section{A PSICANÁLISE CONTRA A PAREDE}

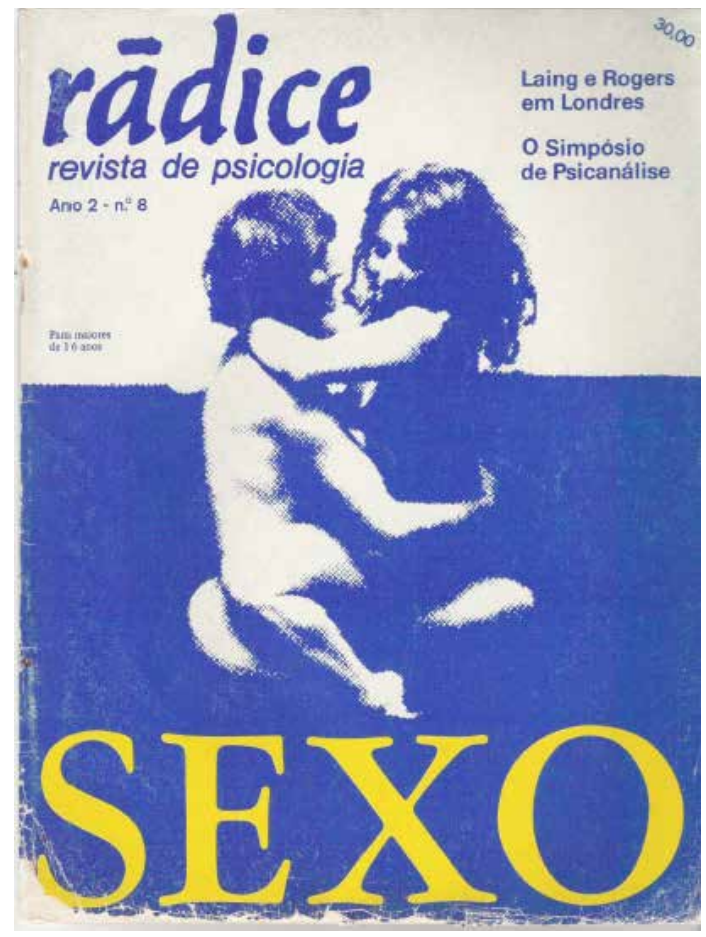
ano 2, n. 8, I978 
"Por que não se fazer uma análise dos analistas? A pesquisa de seus hábitos, origens, meio social; de quanto ganham, onde moram e os lugares que frequentam pode ser reveladora do tipo de ideologia e pensamento desse influente grupo social."

Essa proposta, feita pelo antropólogo Gilberto Velho na mesa-redonda "Psicanálise e Antropologia”, engasgou muita gente e continua de pé. Nesta entrevista, feita alguns dias após o término do Simpósio, Gilberto explicita sua proposta, tece críticas concretas à psicanálise e sugere uma abertura dentro do saber psicanalítico.

Carlos Ralph

\section{A psicanálise contra a parede}

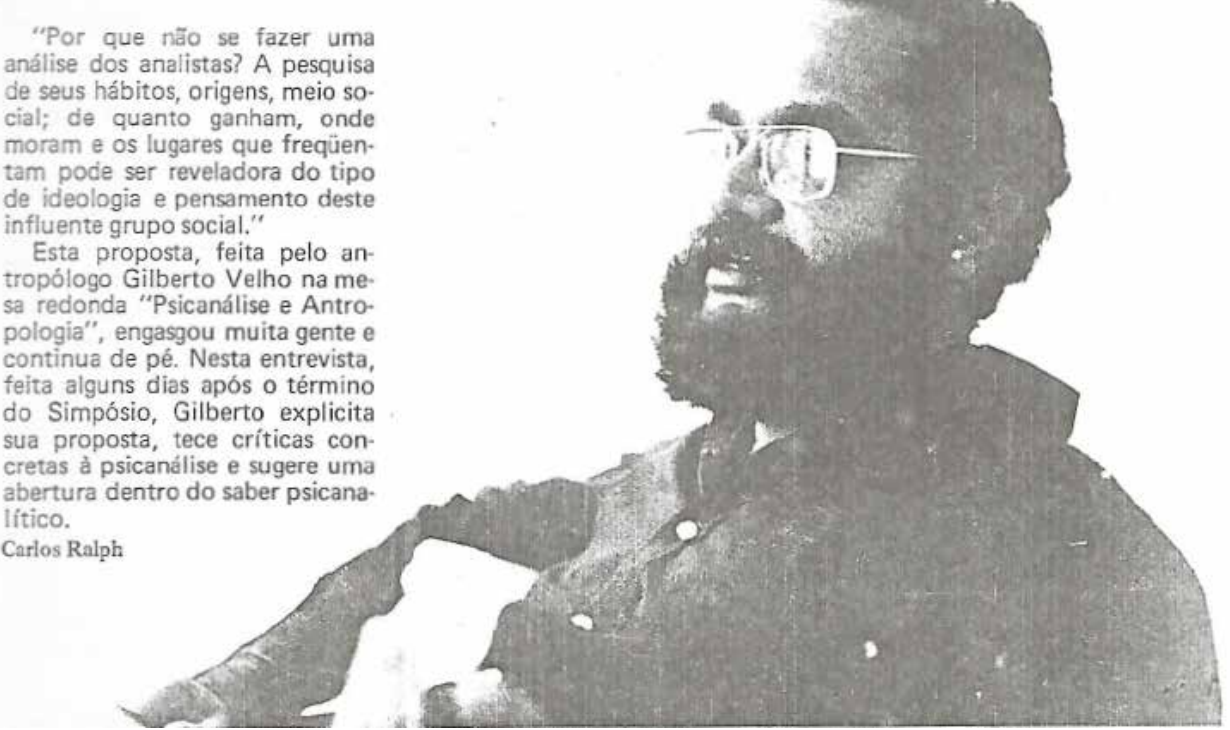

Introdução à entrevista

A psicanálise contra a

parede (Velho, I978: 35) 
Rádice. Gilberto, você fez uma intervenção na mesa-redonda Psicanálise e Antropologia e levantou uma questão importante, que é a de analisar a psicanálise por um ângulo não psicanalítico.

Gilberto Velho. Minha colocação teve a intenção de chamar a atenção para o fato de que a psicanálise, como qualquer outro campo de conhecimento, tem seus limites culturais, sua história e se desenvolveu num determinado quadro social, estando, portanto, limitada por essas experiências como qualquer outra ciência. O problema é que a psicanálise não consegue relativizar sua própria experiência; ela tende a se ver como ciência universal, com padrões e critérios absolutos, com uma noção de normalidade mais ou menos definida em função do fato de ter sido construída a partir de um universo, de uma visão de mundo de uma classe média intelectualizada ocidental. A sacralização da experiência individual, da colocação do indivíduo como foco, é altamente problemática, pois nem todas as estruturas de sociedade têm no indivíduo a sua unidade básica significativa, podendo-se encontrar dentro dessa sociedade grupos sociais, subculturas em que o indivíduo não tem a mesma importância que tem para as classes médias intelectualizadas, que constituem a clientela básica e origem social dos analistas.

R. A psicanálise não só refletiria o individualismo como, ideologicamente, fabricara esse individualismo...

G. V. Ela fabrica o individualismo uma vez que coloca o indivíduo como foco da problemática. Toda sociedade tem seu indivíduo biológico, que chamamos de agente empírico, mas nem todas as sociedades transformam esse agente empírico no seu elemento fundamental, na unidade fundamental da vida social, enfatizando ao máximo sua experiência particular. Em outras sociedades, estruturas, esse indivíduo é dissolvido em unidades maiores, sejam famílias, clãs, linhagens. O indivíduo, aí, faz parte de um todo que é realmente mais significativo.

A psicanálise surge, de certa maneira, dentro das necessidades de uma sociedade individualista, que é capitalista, competitiva, que tem no indivíduo a medida de todas as coisas, e produz (a psicanálise) cada vez mais essa individualidade. Tudo passa a ser interpretado e estudado em função de experiência individual; a ideia de que existe uma "essência" individual quase pode ser desenvolvida... Tudo isso para mim é problema. É problema não só a psicanálise perceber que não é universal, que não vale para todas as culturas e sociedades, como dentro de nossa própria sociedade ela ver que não tem esse valor absoluto. Isso sobressai quando você pensa em camadas de baixa renda, em que você tem outras formas de perceber a sociedade, outras vivências, crenças, visões de mundo e uma série de coisas que dificultam muito a intervenção ou 
a transa analítica. Existe uma falta de empatia para com experiências sociais e culturais diferentes daquelas que são vividas pelos analistas no seu meio, que é muito restrito, particular e redundante.

R. A origem de classe dos analistas determinaria seu tipo de atuação?

G. V. Acho que as pessoas podem até dar a volta por cima sobre a origem, mas a profissão de analista fecha mesmo. Vamos tentar imaginar que um analista tenha uma origem de classe diferente, vamos dizer popular; o problema é que no momento em que ele entra no circuito, ele entra num circuito fechado, conservador e impermeável. As sociedades funcionam de uma maneira tão fechada, que ele teria pouca força, muito pouca capacidade de mudar. Essas sociedades têm um poder muito grande e procuram controlar muito o seu saber, a exclusividade sobre esse saber. A maneira como as pessoas são recrutadas - não falo nem na questão do dinheiro que é preciso muito para pagar o tratamento, para a análise didática -, mas a própria rede de relações pela qual os indivíduos são conectados é de difícil acesso, é preciso alguém para indicar e sugerir, formando no fim uma panelinha, que são as sociedades psicanalíticas. Essas, ao lado de, sem dúvidas, defenderem doutrinas, valores e crenças científicas, também são grupos de pressão, de interesses. São sociedades não simplesmente de cientistas ou humanistas desprendidos que se reúnem para estudar e formar interesse em uma escola, mas grupos de interesse que disputam mercado, que procuram se legitimar, que estão lutando por dinheiro, poder, prestígio. Quando falo isso não estou querendo diminuir, desmoralizar; isto existe em qualquer grupo social, mas, se os analistas não tiverem condições de reconhecer que isso existe, vão ficar desempenhando um papel absolutamente obtuso, de santos, magos, sacerdotes, e não vão nunca perceber que são agentes sociais, seres humanos que desempenham papéis sociais.

R. Existe uma postura, uma política de segredo.

G. V. Essa política de segredo, que em nome de uma ética analítica pretenderia estar protegendo também os analisandos, com o objetivo de fazer com que a terapia seja mais eficaz, na verdade está protegendo muito mais as próprias sociedades, os próprios analistas. Na minha opinião, e não falo só com relação aos analistas, a comunidade deve ter oportunidade e direito de controlar médicos e pessoas que, de uma maneira ou outra, têm algum poder para afetar sua vida. Não é só governo não, mas também pessoas, agências e instituições que interferem no cotidiano das pessoas.

R. Que tipo de controle poderia haver?

G. V. Basicamente acho que as sociedades têm que se abrir mais, se expor mais. Debater não só com outros especialistas, mas com sua clientela, que deve discutir não só com o seu, mas com outros analistas. Discutir tratamentos, noções 
de normalidade, experiências de vida diferentes. Eu quero saber como funciona supervisão, se são realmente efetivas. É preciso saber se existem condições, até em termos de tempo, para que um supervisor acompanhe os casos da pessoa que ele supervisiona, se ele é capaz de acompanhar I5, 20 casos... O fato objetivo é que ficam analisando muita gente, e até que ponto é possível haver um controle, uma supervisão efetiva?

Eu não sou contra a manutenção do sigilo terapêutico e não tenho uma fórmula mágica para resolver essa questão, mas sei que de alguma maneira é preciso que o analisando não fique de pés e mãos atados e entregue aos analistas, perdendo a liberdade que ele possa desejar. Ora, não é só o analista que pode sentir dificuldade no tratamento que está fazendo e pedir socorro a seu supervisor ou a seus pares; o cliente também pode estar sentindo dificuldades, e não existem canais abertos para esse cliente poder se certificar, ter melhores informações que possam possibilitar que sua análise seja mais efetiva, proveitosa. Então, acho que temos que chegar a um meio-termo em que estejam protegidos a qualidade profissional, seus critérios, os profissionais propriamente ditos, dentro de seu mundo, mas que também haja mais canais de comunicação, mais veículos, mais circulação de ideias, que haja mais oportunidade de conferir.

R. Essa organização atual não prejudicaria até a relação terapêutica?

G. V. Não quero cair numa atitude negativa em relação à análise, nem estou querendo dizer que as sociedades são centros de corrupção, retrógados. Existem pessoas esplêndidas nelas, mas a maneira como estão organizadas é prejudicial à própria qualidade do trabalho deles porque, como Peter Fry falou, fica um negócio como feiticeiro, pai de santo. A eficácia do pai de santo, por exemplo, tem uma de suas razões no fato de que ele conhece muito bem o mundo social dos clientes, ele vive aquilo. O que me assusta com relação às sociedades é também a vida que os analistas têm, que especialmente no Rio é uma vida muito limitada, um círculo muito fechado. Eles têm um conhecimento teórico mais ou menos fechado em torno de uma teoria mais ou menos acabada, que tem certas pretensões à exclusividade em relação a determinadas áreas do comportamento, e, por outro lado, têm pouca empatia em relação a experiências diferentes das deles. Não têm condições de perceber e sacar vivências não só de camadas de baixa renda, mas também de pessoas da mesma classe social que tenham tido uma trajetória diferente, um estilo de vida pouco convencional. Acho que a psicanálise é um tipo de conhecimento, uma técnica, uma terapia que, sem dúvida, em relação a uma série de aspectos do comportamento humano, representa um progresso enorme, mas o que não pode acontecer é cair-se nesse exclusivismo analítico, nesse dogmatismo, numa explicação de mundo unilateral em que você procura explicar tudo por meio de um discurso muito fechado, dar conta de tudo mediante um sistema de classificação muito particular que não dá conta de muita coisa. 
R. Em função disso que estamos falando, como você situaria o Ibrapsi?

G. V. Eu tenho dificuldades de situar o Ibrapsi, mas acho que as pessoas que estão ligadas a ele se propõem a voltar-se para e preocupar-se com problemas sociais. A princípio isso é bom, assim como o fato de se proporem a debater e estudar outras disciplinas. Se o Ibrapsi vai dar certo, se não vai, se vai ser consequente com o simpósio ou não, são problemas interessantes para se pensar, mas o que achei importante foi que se abriu no simpósio uma área para discussão, uma área muito fechada, sacralizada, tabu.

R. Falando nele, como você viu a participação dos convidados nacionais neste simpósio carregado de estrelas?

G. V. Tanto em termos de ciência social como de outros campos de conhecimento que ali foram discutidos, o que vi foi uma produção nacional de alto nível, sem dever nada ao que foi apresentado pelos estrangeiros.

R. A cobertura jornalística do simpósio foi bastante voltada para os convidados de fora. Shere Hite foi entrevistada por todos os jornais e revistas, enquanto os daqui tiveram uma cobertura mais apagada, concorda?

G. V. Existiu o problema dos organizadores, que tinham investido uma quantia grande e precisavam ganhar dinheiro, então nesse sentido tinham que jogar muito em cima das estrelas internacionais. Pode-se lamentar, mas de certa forma é compreensível. A imprensa, porém, é muito culpada disso - e posso falar de camarote, porque minha participação foi bastante badalada e coberta -, porque não estava interessada em entrevistas nacionais. Não entrevistaram ninguém daqui, afora os organizadores do congresso. É o lado da imprensa que diz que fulano é notícia então tem que entrevistar o fulano, sem estar interessada em descobrir, verificar se uma pessoa que não seja conhecida esteja dizendo coisas tão ou mais importantes.

R. E a imprensa tocou em "colonialismo cultural"...

G. V. São eles sempre que fazem isso com mais vigor. Acho que cabe a publicações como Rádice tentar de certa maneira corrigir isso, porque da grande imprensa não se pode esperar muita coisa...

R. As intervenções que Guattari, Castel e Basaglia fizeram foram demolidoras da psicanálise, desacreditadoras enquanto conteúdo dito num determinado momento. Na verdade não serviram para propósitos exatamente opostos por fortalecer algo que estavam preocupados em destruir?

G. V. Acho que de certa maneira a vinda das grandes celebridades serviu de fato para legitimar a existência de certas instituições. Se chama essas pessoas, você quase assina um documento se dizendo aberto, crítico, tolerante... esse é um lado da questão; se, porém, as pessoas que assumirem esse tipo de posi- 
cionamento não cumprirem um mínimo de expectativas, vão se dar mal, porque existe uma clientela potencial do Ibrapsi que vai cobrar uma postura diferente; e se até certo ponto não corresponderem a essas expectativa vão se dar mal também em termos econômicos, financeiros, entende? Para competir com as sociedades já estabelecidas, eles vão ter que ser mais consequentes em relação às coisas que foram ditas, colocadas.

R. E com relação ao simpósio?

G. V. Como participante, peguei apenas partes do simpósio, mas o que vi foi basicamente de bom nível. Talvez tenha tido sorte, pois vi gente reclamando dos cursos. Em termos de nível científico, intelectual e consistência, a performance mais fraca que vi foi a de Shere Hite. Achei também que as pessoas revelaram maior amadurecimento e capacidade crítica. Por exemplo a atitude da plateia em relação a Shere Hite no dia do debate com Peter Fry. Uma plateia esmagadora de mulheres, e Shere Hite quase foi vaiada ao se negar a discutir com ele porque ele era do sexo masculino. Quer dizer, foram capazes de distinguir o que havia de demagogia e seriedade. Essas pessoas vão ser capazes de cobrar e ter expectativas razoáveis em relação não só ao Ibrapsi, mas também a outros grupos, sociedades etc., que resolvam aparecer com uma bandeira de interdisciplinaridade e preocupações culturais. A plateia reagiu muito bem, de um modo geral, diante do espetáculo. O público presente, em termos de performance, talvez tenha tido a melhor de todas.

R. Um dos comentários mais frequentes é que estava havendo um ato público de mea culpa da psicanálise.

G. V. Realmente houve. Eu, aliás, procurei dizer que chega de ritual de expiação; não tem sentido ficar batendo no peito dessa maneira. O que é preciso é procurar formas concretas de atuação e aperfeiçoamento. Fiz uma proposta concreta de se fazer uma análise dos analistas, de eles admitirem ser pesquisados e estudados, de que se faça um questionamento no bom sentido a respeito dessa ocupação, desse mundo analítico. Acho que isso poderia se traduzir em seminários, discussões, trazendo representantes das diversas sociedades para debater publicamente, diante de estudantes, clientes, comunidade. Explicitar quais as posições básicas, doutrinas, depois debates, perguntas. Parece uma coisa utópica, mas a partir desse simpósio não é tão utópica assim não.

R. Que sugestões poderiam ser dadas para um próximo simpósio dessa envergadura?

G. V. Existem pessoas que poderiam ser chamadas e que não foram. Pensei no Thomas Scheff, por exemplo, que está desenvolvendo um trabalho importante e não foi trazido porque aqui é pouco conhecido, não dá ibope; no entanto, na área de doença mental é tão importante quanto Goffman. Outra coisa que po- 
674

deria ser aperfeiçoada seria a composição das mesas. Poderiam ser colocadas pessoas de tradições diferentes, como Basaglia e Goffman, Becker e Castel; quer dizer, um americano e um europeu, tradições diferentes. Talvez dinamizasse mais. Outra crítica que se pode fazer é que muitos temas foram tocados en passant, não puderam ser aprofundados em relação a uma série de aspectos. Faltou tempo. Seria interessante dar continuidade a essas atividades organizando-se pequenos seminários com grupos de professores, pesquisadores ou seja lá o que for, para aprofundar certos temas.

O Simpósio de certa maneira foi uma grande mistura, um grande trailler com alguns aspectos circenses e com algumas coisas esplêndidas. O problema é saber agora se vamos conseguir, por intermédio do Ibrapsi ou de outras instituições, aprofundar e continuar o debate, trazendo também pessoas que não puderam participar.

Recebido em 26/Io/20I6| Aprovado em 26/10/20I6

Felipe Magaldi possui graduação em Ciências Sociais pelo IFCS-UFRJ, mestrado em Antropologia pela UFF e doutorado em Antropologia Social pelo Museu Nacional-UFRJ. Atualmente é pós-doutorando no Instituto de Antropología de Córdoba/UNC-Conicet. Desenvolve pesquisas nas áreas de antropologia urbana, da saúde e do Estado, com ênfase em saúde mental e direitos humanos. É autor do livro Frestas estreitas: uma etnografia no Museu de Imagens do Inconsciente (2018), selecionado para publicação pela Coleção Primeiros Campos, do PPGA-UFF. 


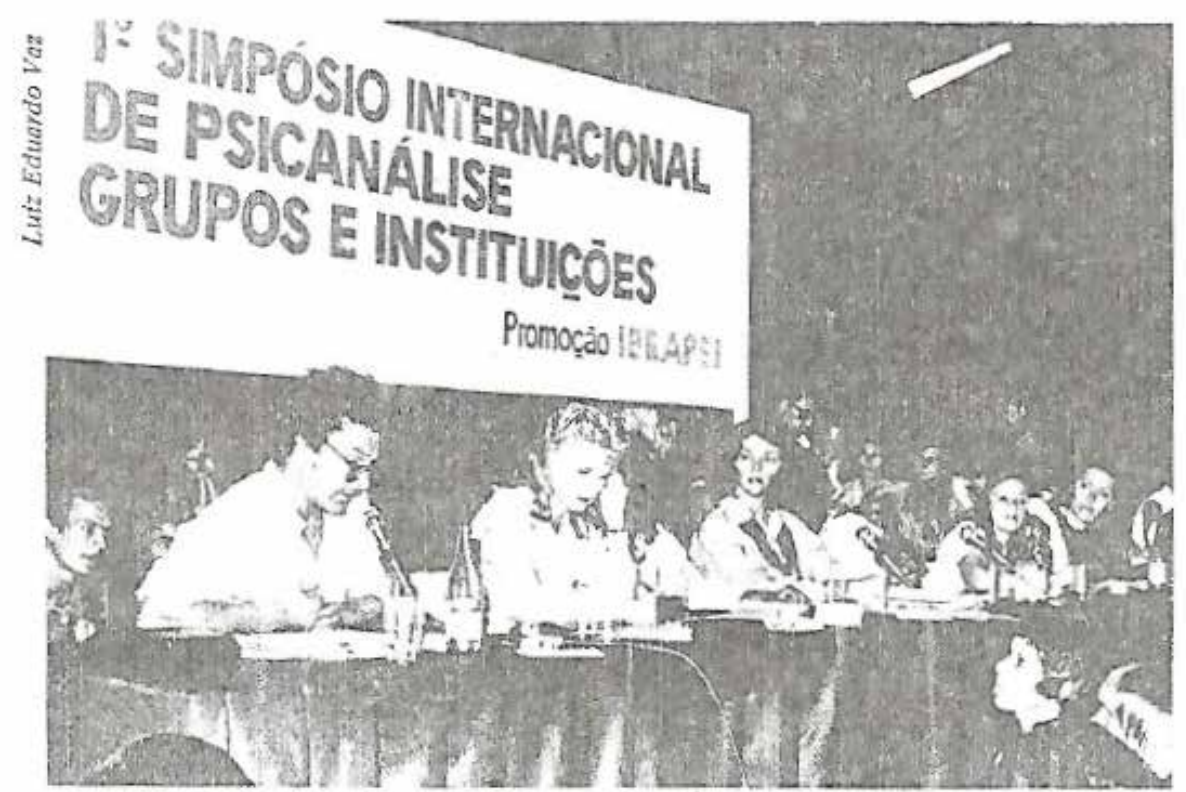

Peter Fry, Shere Hite e as brasileiras. Diferenças além do sexo

Io Simpósio do Ibrapsi (Velho, I978: 37)

As "brasileiras" em questão eram as feministas

históricas Leila Linhares Barsted, Branca Moreira Alves e Jaqueline Pitanguy 


\section{NOTAS}

I Conforme consta na Base Minerva - fundo virtual de dados bibliográficos da UFRJ -, I I edições da revista Rádice estão disponíveis no acervo da Biblioteca Francisca Keller, vinculada ao PPGAS do Museu Nacional. O número aqui citado, não obstante, não se encontra no referido conjunto.

2 Desde então, outras pesquisas a respeito do tema têm surgido, como a de Schprejer (2009), defendida no Instituto de Medicina Social da Uerj.

3 Gilberto Velho faz referência ao mesmo simpósio em seu artigo Becker, Goffman e a antropologia brasileira, publicado na revista Ilha (Velho, 2002), em que descreve a contribuição particular desses dois cientistas sociais norte-americanos, com curiosos detalhamentos sobre seus temperamentos.

\section{REFERÊNCIAS BIBLIOGRÁFICAS}

Duarte, Luiz Fernando Dias. (2000). Dois regimes históricos das relações da antropologia com a psicanálise no Brasil: um estudo de regulação moral da pessoa. In: Amarante, Paulo (org.). Ensaios: subjetividade, saúde mental, sociedade. Rio de Janeiro: Ed. Fiocruz.

Duarte, Luiz Fernando Dias. (1996). Antropología médica, antropología de la persona y la salud em Brasil. Entrevista concedida a Santiago Wallace. Publicar, 5/6, p. IOI-II3. Duarte, Luiz Fernando Dias. (I986). Da vida nervosa nas classes trabalhadoras urbanas. Rio de Janeiro: Zahar/CNPq. Figueira, Sérvulo. (I98I). O contexto social da psicanálise. Rio de Janeiro: Francisco Alves.

Figueira, Sérvulo (org.). (I980). Psicanálise e ciências sociais. Rio de Janeiro: Francisco Alves.

Figueira, Sérvulo (org.). (I978). Sociedade e doença mental. Rio de Janeiro: Campus.

Figueira, Sérvulo \& Velho, Gilberto (orgs.). (I98I). Família, psicologia e sociedade. Rio de Janeiro: Campus.

Russo, Jane. (2004). Uma leitura antropológica do mundo 'psi'. Mnemosine, I/o, p. 38-43. 
Santos, Alessandra Daflon dos. (2008). Rádice muito prazer: crônicas do passado e do futuro da psicologia no Brasil. Tese de Doutorado. Programa de Pós-Graduação em Psicologia Social/Universidade do Estado do Rio de Janeiro.

Santos, Alessandra Daflon dos \& Jacó-Vilela, Ana Maria. (2006). Rádice: Passado e Futuro. Psicologia e Sociedade. Porto Alegre, I7/3, p. 24-30.

Schprejer, Pedro de Oliveira. (2009). Corpo, subjetividade e política: o ideário libertário das décadas de 60 e 70 em uma revista de "jornalismo da psicologia". Dissertação de Mestrado. Programa de Pós-Graduação em Saúde Coletiva, Instituto de Medicina Social/Universidade do Estado do Rio de Janeiro.

Velho, Gilberto. (2002). Becker, Goffman e a antropologia brasileira. Ilha, Florianópolis, 4/I, p. 5-I6.

Velho, Gilberto. (I98I). Individualismo e cultura. Rio de Janeiro: Zahar.

Velho, Gilberto. (1978). A psicanálise contra a parede. Entrevista concedida ao comitê editorial da Rádice. Rádice Revista de Psicologia, 2/8, p. 35-37.

Velho, Gilberto (org.). (I974). Desuio e divergência. Rio de Janeiro: Zahar. 


\section{A PSICANÁLISE CONTRA A PAREDE: ENTREVISTA COM GILBERTO VELHO}

Resumo

Trata-se da apresentação e da transcrição de entrevista realizada com o antropólogo Gilberto Velho, publicada em I 978 na revista Rádice. O documento condensa de forma privilegiada algumas das principais questões que perpassavam a agenda da então nascente antropologia urbana no Rio de Janeiro, com particular destaque para sua proposta de abordagem dos saberes psicológicos (psiquiatria, psicologia e psicanálise) sob a égide da problemática indivíduo/sociedade. Na entrevista, realizada poucos dias após o Io Simpósio Internacional do Instituto Brasileiro de Psicanálise, Grupos e Instituições Ibrapsi, o antropólogo deixa entrever que a relação entre antropologia e psicanálise estabelecida nesse contexto estava longe de coincidir com uma aliança pacífica. Tratava-se, antes, de um exercício crítico que, do ponto de vista comparativo das ciências sociais, ensejaria a desestabilização dos pressupostos universalistas dos saberes "psi" e da visão de mundo individualista comprometida com sua difusão.

\section{PSYCHOANALYSIS AGAINST THE WALL: AN INTERVIEW WITH GILBERTO VELHO}

Abstract

This text presents and transcribes an interview with the anthropologist Gilberto Velho, published in 1978 in Rádice magazine. The document provides a unique condensation of some of the main issues that permeated the agenda of the nascent urban anthropology in Rio de Janeiro, with a particular emphasis on its approach to psychological knowledge (psychiatry, psychology and psychoanalysis) under the aegis of the individual/society problematic. In the interview, conducted a few days after the First International Symposium of IBRAPSI (Brazilian Institute of Psychoanalysis, Groups and Institutions), the anthropologist suggests that the relation between anthropology and psychoanalysis established in this context was far from a pacific alliance. Rather, it was a critical exercise that, from the comparative point of view of the social sciences, destabilized the universalistic assumptions of "psi" knowledge and the individualistic worldview involved in its dissemination.
Palavras-chave

Gilberto Velho;

Rádice;

antropologia urbana; individualismo; psicanálise.

Keywords

Gilberto Velho;

Rádice;

urban anthropology;

individualism; psychoanalysis. 